\title{
Mental health of patients with adolescent idiopathic scoliosis and their parents in China: a cross-sectional survey
}

Hai Wang ${ }^{1 \dagger}$, Tao $\mathrm{Li}^{2 \dagger}$, Wangshu Yuan ${ }^{3}$, Zheping Zhang ${ }^{4}$, Jing Wei ${ }^{2}$, Guixing Qiu ${ }^{1}$ and Jianxiong Shen ${ }^{1 *}$

\begin{abstract}
Backgrounds: Adolescent idiopathic scoliosis (AIS) is an adolescent onset spinal deformity, which can negatively affect the mental health of these patients. But no studies about their parental mental health have been reported so far. In this study, the parental mental health of AIS patients and the associated risk factors were evaluated by a cross-sectional survey.

Methods: 64 AIS patients who underwent conservative or surgical treatments in our hospital from April 2017 to March 2018, and their parents were enrolled in the AIS group. 85 parents of healthy children were enrolled in the control group. Depression and anxiety were separately assessed using the Patient Health Questionnaire (PHQ-9) and the Generalized Anxiety Disorder 7-item scale (GAD-7). Spearman correlation coefficients were first estimated to investigate the relationships among the parental PHQ-9/GAD-7 scores and the patient's PHQ-9/GAD-7 scores in the AIS group. Then, the morbidities of the parental probable major depressive disorder (pMDD, PHQ score $\geq 10$ ) and probable general anxiety disorder ( $p G A D, G A D-7$ score $\geq 10$ ) were compared between the AIS and control groups. Third, the potential risk factors for parental pMDD or pGAD in the AIS group were compared using the chi-squared test or Student's t-test, respectively. Finally, the uneven distributive variates were analyzed using the binary logistic regression model.
\end{abstract}

Results: Both parental depression and anxiety were moderately associated with those of the patients $(r=0.448 \sim 0.515$, $p<0.01$ ) in the AIS group, respectively. The morbidities of parental pMDD and PGAD in the AIS group were $14.1 \%$, significantly higher than those in the control group ( $\mathrm{pMDD}=4.7 \%, p=0.045 ; \mathrm{PGAD}=3.5 \%, p=0.019)$. A Cobb angle of the major curve $\geq 50^{\circ}(p=0.034$, odds ratio $[O R]=8.264)$, patients with $\operatorname{pMDD}(p=0.018, \mathrm{OR}=17.576)$, and low education level of the parents $(p=0.026, \mathrm{OR}=0.122)$ were the risk factors of parental pMDD. Household income $<8000 \mathrm{rmb} /$ month was the risk factor for parental $\operatorname{pGAD}(p=0.021)$.

Conclusions: The morbidities of PMDD and PGAD in parents of AIS patients were higher than those in parents of healthy children. Parental depression and anxiety were closely associated with their children's depression and anxiety. Therefore, the parental mental health of AIS patients should be paid attention to, especially for those parents with risk factors.

Keywords: Adolescent idiopathic scoliosis (AIS), Parents, Depression, Anxiety, Mental health

\footnotetext{
* Correspondence: sjxpumch@163.com

${ }^{+}$Hai Wang and Tao Li contributed equally to this work.

${ }^{1}$ Department of Orthopaedic Surgery, Peking Union Medical College Hospital,

Peking Union Medical College and Chinese Academy of Medical Sciences,

Beijing, China

Full list of author information is available at the end of the article
}

(c) The Author(s). 2019 Open Access This article is distributed under the terms of the Creative Commons Attribution 4.0 International License (http://creativecommons.org/licenses/by/4.0/), which permits unrestricted use, distribution, and reproduction in any medium, provided you give appropriate credit to the original author(s) and the source, provide a link to the Creative Commons license, and indicate if changes were made. The Creative Commons Public Domain Dedication waiver (http://creativecommons.org/publicdomain/zero/1.0/) applies to the data made available in this article, unless otherwise stated. 


\section{Backgrounds}

Scoliosis is a three dimensional deformation of the spine with a Cobb angle of the major curve $\geq 10^{\circ}$ in a standing anteroposterior X-ray image [1]. About $85 \%$ of these individuals are idiopathic scoliosis with no known etiology [2]. According to the age of onset, idiopathic scoliosis can be classified as infantile, juvenile, and adolescent [1]. Among them, adolescent idiopathic scoliosis (AIS) is the most common type, with a prevalence rate of approximately 2 to $3 \%$ based on data from the school screening studies $[3,4]$.

AIS can negatively affect the mental health of the patients, especially resulting in depression [5]. Several instruments, such as the Short-Form-36(SF-36), the Bad Sobernheim Stress Questionnaire (BSSQ), and the Scoliosis Research Society 22 Questionnaire (SRS-22), have been used to assess the mental health of AIS patients [6, 7]. Their parents, the close family caregivers, might also be affected because they have to take on new responsibilities, or give up past activities due to the stress of their children's deformities and mental health alterations. Several previous studies have confirmed that the parents of the AIS patients may also be affected by this deformity [8-13]. The parental anxiety level of AIS patients decreased significantly from preoperative to postoperative stages but still remained high [13]. The parents view the deformity differently from the patient, as they overestimate the patient's stress level, and have greater concerns and expectations regarding scoliosis surgery $[8,11,12]$.

Common mental disorders (CMDs) such as depression and anxiety can have implications for long-term health outcomes associated with increased fatigue, impaired long-term disease activity and physical disability [14]. Therefore, it is very important for scoliosis surgeons to recognize and address parental CMDs when parents accompany the AIS patient to see a doctor. In this study, we hypothesized that the parental mental health of patients with AIS might be negatively affected and related to some potential risk factors, such as patients' factors, socio-economic factors, and the severity of the deformity.

\section{Materials and methods \\ Samples}

This cross-sectional descriptive study was conducted in the Department of Orthopaedic Surgery and Department of Rehabilitation in the authors' hospital, between April, 2017 and March, 2018. A total of 64 consecutive AIS patient (aged 11-18 years old)-parent pairs were enrolled in this study. All the AIS patients were diagnosed by two spine deformity surgeons based on their medical history and images. There were 5 males and 59 females in the patient group and 17 fathers and 47 mothers in the parent group. A total of 85 parents (23 fathers and 62 mothers) of health children with age of $11-18$ years old was enrolled in the control group. All the participants were orally informed, and the parents gave their written consent.

\section{Procedures}

All the questionnaires were administered and data collected before operation or physiotherapy. Questions about socio-demographic data including household income, marital status, employment, and education were answered by parents. Brace history was defined as "yes", referring to Misterska's report [12], if a patient ever underwent the brace application for at least $12 \mathrm{~h}$ a day for more than 1 month before the survey. The deformity data were measured by two experienced surgeons based on the X-ray images, including the Cobb angle of the major curve, frontal balance, and shoulder height.

\section{Instruments}

Depression and anxiety of all the participants were separately evaluated using a nine-item Patient Health Questionnaire (PHQ-9) and a seven-item Generalized Anxiety Disorder scale (GAD-7) in Chinese.

The PHQ-9 is a widely used self-report screening tool for depression based on the Diagnostic and Statistical Manual of Mental Disorders-IV (DSM-IV) criteria [15]. The tool consists of 9 items that assess whether the symptoms have bothered the individual during the previous 2 weeks. The summed score ranges from 0 to 27 , and can be categorized into 4 categories: minimal (0 4), mild (5 9), moderate $(10 \sim 14)$, and severe $(\geq 15)$. In most studies, a cutoff point of 10 has been accepted for the diagnostic criteria of probable major depressive disorder (pMDD) [16]. Its pooled sensitivity and specificity were 0.78 and 0.87 , respectively. The reliability and validity of its Chinese version has been confirmed previously [17].

The GAD-7 has been shown to be a valid and effective measure of anxiety in the general population [18]. The item scales of this measure, based on DSM-IV criteria, focus on the presence of 7 core anxiety symptoms in the last 2 weeks. The total scores range between 0 and 21, and can also be categorized into 4 categories: minimal (0 4), mild (5 9), moderate $(10 \sim 14)$, and severe $(\geq 15)$. A cutoff point of 10 has been set for diagnosing probable generalized anxiety disorder (pGAD) [19]. Its sensitivity and specificity were 0.89 and 0.82 , respectively. The reliability and validity of its Chinese version have also been confirmed previously [17].

\section{Statistics}

Means \pm SDs and ranges of values or proportions were separately used to describe the measurement data and the categorical data. Spearman correlation coefficients were estimated in order to investigate the associations between the parental PHQ-9 scores and GAD-7 scores and PHQ-9/GAD-7 scores of the patients and their 
parents if the scores did not fit normal distribution. For the potential risk factors of the parental pMDD (PHQ-9 $\geq$ 10) or pGAD (GAD-7 $\geq 10)$, group differences were first analyzed using the chi-squared test for the categorical data (sex of patients, Cobb angle of the major curve, planned surgery, pMDD of patients, pGAD of patients, shoulder height, brace treatment, parenthood, education of parents, employment of parents, health insurance, residence, parental marriage, live with parents, and household income) and the independent t-test for the measurement data (age of patients, age of parents, course of disease, and frontal balance). The effects of independent risk factors on pMDD or pGAD were analyzed using the logistic regression model. The data were analyzed using SPSS, version 22.0 (IBM Corp., Armonk, New York, USA). $P<0.05$ was considered statistically significant.

\section{Results}

\section{General characteristics}

A total of 64 AIS patients (age $=14.3 \pm 2.2$ years old; male: female $=5: 59$ ) and their parents (age $=42.4 \pm 4.3$ years old; male: female $=17: 47$ ) were enrolled in this study. The mean Cobb angle of the major curve was $44.2 \pm 18.9^{\circ}$. The general characteristics of the included samples are summarized in Table 1.

\section{PHQ-9 scores and GAD-7 scores}

The mean PHQ-9 and GAD-7 scores of the AIS patients were $4.0 \pm 4.0(0 \sim 16)$ and $2.9 \pm 3.5(0 \sim 19)$, respectively, and the parental mean scores were $4.7 \pm 5.0(0 \sim 20)$ and $4.2 \pm 4.7$ (0 19), respectively. Table 2 shows the distribution of PHQ-9 scores and GAD-7 scores for patients and their parents. There were more parents with severe depressive or anxious symptoms $(\geq 15)$ than patients.

According to the definition of pMDD (PHQ-9 $\geq 10$ ), the morbidities were $7.9 \%(5 / 64)$ and $14.1 \%(9 / 64)$ for the AIS patients and their parents in the AIS group, respectively. The morbidity of the parental pMDD in the AIS group was significantly higher than that in the control group ( $14.1 \%$ vs $4.7 \%, p=0.045$, Table 3$)$. Similarly, the morbidities of pGAD (GAD-7 $\geq 10)$ were $3.2 \%(2 / 64)$ and $14.1 \%$ $(9 / 64)$ for the AIS patients and their parents in the AIS group, respectively. The morbidity of the parental pGAD in the AIS group was significantly higher than that in the control group ( $14.1 \%$ vs $3.5 \%, p=0.019$, Table 3$)$. A total of $17.2 \%(11 / 64)$ parents in the AIS group suffered from pCMDs, and approximately $77.8 \%$ (7/9) of parents with pMDD were also diagnosed with $\mathrm{pGAD}$.

\section{Relationships between PHQ-9 and GAD-7 scores in the AIS group}

The PHQ-9 scores of the parents were strongly correlated with their GAD-7 scores of the parents $(r=0.690$, $p<0.01$, Table 4). The PHQ-9 scores of the parents were
Table 1 The general characteristics of the samples (64 patientparent pairs)

\begin{tabular}{|c|c|}
\hline Variables & Value \\
\hline Age of patients (years old) & $14.3 \pm 2.2$ \\
\hline Sex of patients Male & $5(7.8 \%)$ \\
\hline Female & $59(92.2 \%)$ \\
\hline Brace application Yes & $19(29.7 \%)$ \\
\hline No & $45(70.3 \%)$ \\
\hline Cobb angle of the major curve $\left(^{\circ}\right)$ & $44.2 \pm 18.9$ \\
\hline Frontal balance (mm) & $11.2 \pm 10.1$ \\
\hline Shoulder height Equal & $16(25.0 \%)$ \\
\hline Unequal & $48(75.0 \%)$ \\
\hline Age of parents (years old) & $41.7 \pm 3.7$ \\
\hline Sex of parents Male & $17(26.6 \%)$ \\
\hline Female & $47(73.4 \%)$ \\
\hline Health insurance (Yes) & $51(79.7 \%)$ \\
\hline Residence City & $55(85.6 \%)$ \\
\hline Countryside & $9(14.4 \%)$ \\
\hline Marriage of parents Married & $58(90.6 \%)$ \\
\hline Divorced & $5(7.8 \%)$ \\
\hline Widowed & $1(1.6 \%)$ \\
\hline Live with parents Yes & $61(95.3 \%)$ \\
\hline No & $3(4.7 \%)$ \\
\hline Household income $\leq 4000 \mathrm{rmb} /$ month & $17(26.6 \%)$ \\
\hline 4000 8000 rmb/month & $25(39.1 \%)$ \\
\hline$\geq 8000 \mathrm{rmb} / \mathrm{month}$ & $22(34.4 \%)$ \\
\hline Employment of father Yes & $53(84.1 \%)$ \\
\hline No & $10(15.9 \%)$ \\
\hline Employment of mother Yes & $40(62.5 \%)$ \\
\hline No & $24(37.5 \%)$ \\
\hline Education of father Primary school & $1(1.6 \%)$ \\
\hline Junior high school & $11(17.5 \%)$ \\
\hline Senior high school & $19(30.2 \%)$ \\
\hline University & $32(50.8 \%)$ \\
\hline Education of mother Primary school & $1(1.6 \%)$ \\
\hline Junior high school & $19(29.7 \%)$ \\
\hline Senior high school & $20(31.3 \%)$ \\
\hline University & $24(37.5 \%)$ \\
\hline
\end{tabular}

rmb Renminbi

moderately correlated with the PHQ-9 scores and the GAD-7 scores of the patients $(r=0.499$ and 0.448 , respectively; $p<0.01$, Table 4). Additionally, the GAD-7 scores of the parents were also moderately associated with the PHQ-9 scores and the GAD-7 scores of the patients $(\mathrm{r}=0.515$ and 0.469 , respectively; $p<0.01$, Table 4$)$. Upon further comparison, the maternal PHQ-9 scores and GAD-7 scores were higher than the paternal scores, 
Table 2 PHQ-9 scores and GAD-7 scores of the patients and their parents

\begin{tabular}{lllll}
\hline & $\begin{array}{l}\text { Minimal } \\
(0 \sim 4)\end{array}$ & Mild (5 9) & $\begin{array}{l}\text { Moderate } \\
(10 \sim 14)\end{array}$ & $\begin{array}{l}\text { Severe } \\
(\geq 15)\end{array}$ \\
\hline $\begin{array}{l}\text { Patients } \\
\text { PHQ-9 score }\end{array}$ & $39(60.9 \%)$ & $20(31.3 \%)$ & $4(6.3 \%)$ & $1(1.6 \%)$ \\
GAD-7 score & $49(76.6 \%)$ & $13(20.3 \%)$ & $1(1.6 \%)$ & $1(1.6 \%)$ \\
Parents & & & & \\
PHQ-9 score & $39(60.9 \%)$ & $16(25.0 \%)$ & $4(6.3 \%)$ & $5(7.8 \%)$ \\
GAD-7 score & $44(68.8 \%)$ & $11(17.2 \%)$ & $5(7.8 \%)$ & $4(6.3 \%)$ \\
\hline
\end{tabular}

but the difference was only significant for the PHQ-9 scores (PHQ-9 scores:5.5 \pm 5.3 vs $2.5 \pm 2.8, p=0.005$; GAD-7 scores: $4.5 \pm 5.1$ vs $3.4 \pm 3.1, p=0.403)$.

\section{Risk factors for parental pMDD in the AIS group}

All the potential risk factors were first compared between the parents with and without pMDD using the chi-squared test or the independent t-test. As shown in Table 5, a Cobb angle of the major curve $\geq 50^{\circ}$, pMDD in patients, low education level of the parents, and household income $<8000 \mathrm{rmb} /$ month were significantly associated with parental pMDD $(p=0.022,0.017,0.022$, and 0.021 , respectively). Further, the binary logistic regression results revealed that a Cobb angle of the major curve $\geq 50^{\circ}(p=0.034$, odds ratio $[\mathrm{OR}]=8.264)$, pMDD of patients $(p=0.018, \mathrm{OR}=17.576)$, and low education level of the parents $(p=0.026, \mathrm{OR}=0.122)$ were the independent risk factors for parental pMDD (Table 6).

\section{Risk factors for parental pGAD in the AIS group}

First, the potential risk factors were also first compared between the parents with and without pGAD using the chi-squared test or the independent $t$-test. The results showed that only household income $<8000 \mathrm{rmb} /$ month was significantly associated with parental pGAD $(p=0.021$, Table 7). Therefore, it was not necessary to conduct a binary logistic regression test to eliminate the influences of farraginous factors. Household income $<8000 \mathrm{rmb} /$ month was the independent risk factor for parental pGAD.

Table 3 The comparative test results of the parental mental health between the AIS group and the control group

\begin{tabular}{llll}
\hline Variables & AIS $(n=64)$ & Control $(n=85)$ & $p$ \\
\hline Parental Age (years old) & $42.5 \pm 4.3$ & $41.9 \pm 4.6$ & 0.420 \\
Sex Male & $17(26.6 \%)$ & $23(27.1 \%)$ & 0.946 \\
$\quad$ Female & $47(73.4 \%)$ & $62(72.9 \%)$ & \\
pMDD Yes & $9(14.1 \%)$ & $4(4.7 \%)$ & 0.045 \\
$\quad$ No & $55(85.9 \%)$ & $81(95.3 \%)$ & \\
PGAD Yes & $9(14.1 \%)$ & $3(3.5 \%)$ & 0.019 \\
$\quad$ No & $55(85.9 \%)$ & $82(96.5 \%)$ & \\
\hline
\end{tabular}

Table 4 Spearman Correlation analysis of PHQ-9 scores and GAD-7 scores in the AIS group

\begin{tabular}{lll}
\hline & \multicolumn{2}{l}{ Parents } \\
\cline { 2 - 3 } & PHQ-9 score & GAD-7 score \\
\hline Parents & - & $0.690^{* *}$ \\
PHQ-9 score & $0.690^{* *}$ & - \\
GAD-7 score & & \\
Patients & $0.499^{* *}$ & $0.515^{* *}$ \\
PHQ-9 score & $0.448^{* *}$ & $0.469^{* *}$ \\
\hline
\end{tabular}

**significant at the level of $p<0.01$

\section{Discussion}

In this study, we were able to depict a remarkable increase in the incidence of pCMDs (pMDD and pGAD) prevalence among the parents of AIS patients. Morbidities of both parental pMDD and pGAD in the AIS group were significantly higher than those in the control group. Previously, AIS has been regarded as a chronic condition that affects an adolescent's bodily configuration, consequently leading to alterations in psychological health and lifestyle $[5,7]$. The parents of these patients, the closest and long-term caregivers, might be forced to make changes in their own lives, take on new responsibilities, or give up past activities due to the stress of their children's illness and alterations. The Caregiving Career/Stress Process model suggests that life events can lead to persistent negative changes in people's roles that wear away at desirable elements of self-concept with the arousal of stress [20, 21]. Once the demands and obstacles that exceed or push parental capacity to adapt to the limit, the mental health of the parents can be negatively affected. The relationship between the parental perception of how difficult it is to care for the child and the feelings of depression has been confirmed and might explain why the parental anxiety of AIS patients still remains high after surgery [13, 22].

In the clinic, deformity surgeons should pay attention to the parental mental health of AIS patients when diagnosing and treating these patients. Because CMDs can not only deteriorate the quality of life and social functioning but also cause the development and exacerbation of chronic illness [23]. It has been confirmed that cardiovascular disease, diabetes, asthma, smoking, and obesity are all significantly associated with anxiety and depression [24].

Depression and anxiety in the parents shared a very close relationship. More than half of the parents diagnosed with pMDD also had pGAD. Depression and anxiety almost always go together, as depression tends to be past-oriented, whereas anxiety is future-oriented $[25,26]$. Therefore, we should meanwhile focus on depression and anxiety in parents. 
Table 5 Univariate analysis results of parental pMDD in the AIS group

\begin{tabular}{|c|c|c|c|}
\hline \multirow[t]{2}{*}{ Variables } & \multicolumn{2}{|l|}{ PHQ-9 score } & \multirow[t]{2}{*}{$p$} \\
\hline & $<10(n=55)$ & $\geq 10(n=9)$ & \\
\hline Age of patients (years old) & $14.3 \pm 2.1$ & $14.8 \pm 2.6$ & 0.511 \\
\hline Course of disease (months) & $18.5 \pm 20.5$ & $24.2 \pm 27.8$ & 0.464 \\
\hline Frontal Balance (mm) & $11.0 \pm 10.3$ & $13.0 \pm 8.8$ & 0.575 \\
\hline Major Curve $<50^{\circ}$ & 37 (94.9\%) & $2(5.1 \%)$ & $0.022^{*}$ \\
\hline$\geq 50^{\circ}$ & $18(72.0 \%)$ & 7 (28.0\%) & \\
\hline Sex of patients Male & $3(60.0 \%)$ & $2(40.0 \%)$ & $0.141^{*}$ \\
\hline Female & $52(88.1 \%)$ & $7(11.9 \%)$ & \\
\hline Planed surgery Yes & $29(82.9 \%)$ & $6(17.1 \%)$ & $0.494^{*}$ \\
\hline No & $26(89.7 \%)$ & $3(10.3 \%)$ & \\
\hline MDD of patients No & $53(89.8 \%)$ & $6(10.2 \%)$ & $0.017^{*}$ \\
\hline Yes & $2(40.0 \%)$ & $3(60.0 \%)$ & \\
\hline GAD of patients No & $54(87.1 \%)$ & $8(12.9 \%)$ & $0.263^{*}$ \\
\hline Yes & $1(50.0 \%)$ & $1(50.0 \%)$ & \\
\hline Shoulder height Equal & $14(87.5 \%)$ & $2(12.5 \%)$ & $1.000^{*}$ \\
\hline Unequal & $41(85.4 \%)$ & $7(14.6 \%)$ & \\
\hline Brace treatment Yes & $15(78.9 \%)$ & $4(21.1 \%)$ & $0.432^{*}$ \\
\hline No & $40(88.9 \%)$ & $5(11.1 \%)$ & \\
\hline Age of parents & $42.7 \pm 4.3$ & $41.0 \pm 3.8$ & 0.270 \\
\hline Parenthood Father & $16(94.1 \%)$ & $1(5.9 \%)$ & $0.424^{*}$ \\
\hline Mother & 39 (83.0\%) & $8(17.0 \%)$ & \\
\hline $\begin{array}{l}\text { Education of parents Primary/ } \\
\text { Junior school }\end{array}$ & $14(70.0 \%)$ & $6(30.0 \%)$ & $0.022^{*}$ \\
\hline Senior school/University & $41(93.2 \%)$ & $3(6.8 \%)$ & \\
\hline Job of parents Yes & 37 (88.1\%) & $5(11.9 \%)$ & $0.480^{*}$ \\
\hline No & $18(81.8 \%)$ & $4(18.2 \%)$ & \\
\hline Health Insurance Yes & $44(86.3 \%)$ & $7(13.7 \%)$ & $1.000^{*}$ \\
\hline No & $11(84.6 \%)$ & $2(15.4 \%)$ & \\
\hline Residence City & $48(87.3 \%)$ & $7(12.7 \%)$ & $0.602^{*}$ \\
\hline Countryside & $7(77.8 \%)$ & $2(22.2 \%)$ & \\
\hline Parental Marriage Married & 49 (84.5\%) & $9(15.5 \%)$ & $0.582^{*}$ \\
\hline Divorced/widowed & $6(100.0 \%)$ & $0(0.0 \%)$ & \\
\hline Live with parents Yes & $53(86.9 \%)$ & $8(13.1 \%)$ & $0.370^{*}$ \\
\hline No & $2(66.7 \%)$ & 1 (33.3\%) & \\
\hline Income $<8000 \mathrm{rmb} /$ month & $32(78.0 \%)$ & $9(22.0 \%)$ & $0.021^{*}$ \\
\hline$\geq 8000 \mathrm{rmb} /$ month & $23(100.0 \%)$ & $0(0.0 \%)$ & \\
\hline
\end{tabular}

* Fisher exact test

Both depression and anxiety in the parents were moderately associated with those in the patients, respectively. There might be two reasons why the psychiatric symptom scores of the parents were associated with similar psychopathology in their children: the heritability and/or the parenting stress [27]. Compared to the mental health status of the fathers, maternal mental health was more
Table 6 Binary logistic regression results of parental pMDD (Method $=\mathrm{LR}$ )

\begin{tabular}{llll}
\hline Variables & $p$ & Odd ratio (OR) & $\begin{array}{l}95 \% \text { confidence } \\
\text { interval (Cl) }\end{array}$ \\
\hline $\begin{array}{l}\text { Cobb angle of the } \\
\text { major curve } \geq 50^{\circ}\end{array}$ & 0.034 & 8.264 & $1.178 \sim 57.947$ \\
MDD of patients & 0.018 & 17.576 & $1.619 \sim 190.772$ \\
Education of parents & 0.026 & 0.122 & $0.019 \sim 0.780$ \\
Household income & 0.051 & $<0.001$ & $<0.001 \sim>999.999$ \\
\hline
\end{tabular}

likely to be elevated, especially for depression. The PHQ-9 scores of the mothers were significantly higher than those of the fathers. Because caregiver stress tends to be higher in mothers, maternal depression is more strongly associated with internalizing problems in children than paternal depression $[28,29]$.

More insight into these risk factors of pMDD or pGAD can facilitate earlier recognition of these parents that may benefit from more intensive treatment. As reported previously, general risk factors for parental psychopathology include financial problems, unemployment, divorce, being a single parenting, and the demographic characteristics of the parent and child [30,31]. Referring to Raina's multidimensional model for examining the determinants of psychological health in the parents of children with health issues [21], these sociodemographic variables and some clinical variables were selected as potential risk factors for pMDD or pGAD to analysis in this study. The results showed that a Cobb angle of the major curve $\geq 50^{\circ}$, patients with pMDD, and low education level of parents were the risk factors for parental pMDD; household income $<8000 \mathrm{rmb} /$ month was the risk factor for parental pGAD.

Parental pMDD was associated with a Cobb angle of the major curve $\geq 50^{\circ}$. A higher Cobb angle of the major curve indicates the possibility of disturbed appearances, curve progression, and severe back pain. All these concerns might arouse or aggravate the parental depression. Otherwise, surgical procedures are often be suggested when the Cobb angle of the major curve is more than $50^{\circ}$. Although planed surgery is not a risk factor for pMDD, it is possible that the fear and burden of surgery may further aggravate the parental depression based on these above mentioned concerns.

Parental pMDD was strongly correlated with patients with pMDD. Parents whose children suffer from psychiatric symptoms are at risk for psychiatric symptoms themselves [26]. As discussed above, parental depression can be affected by their offspring's depression through two pathways: the heritability and/or the parenting stress [27]. Moreover,parents' perceptions of their child's depression regarding their deformity are stronger than their child's own assessment [12]. 
Table 7 Univariate analysis results of parental pGAD in the AIS group

\begin{tabular}{|c|c|c|c|}
\hline \multirow[t]{2}{*}{ Variables } & \multicolumn{2}{|l|}{ GAD-7 score } & \multirow[t]{2}{*}{$p$} \\
\hline & $<10(n=55)$ & $\geq 10(n=9)$ & \\
\hline Age of patients (years old) & $14.2 \pm 2.1$ & $15.0 \pm 2.5$ & 0.325 \\
\hline Course of disease (months) & $18.5 \pm 20.5$ & $24.6 \pm 27.5$ & 0.434 \\
\hline Frontal Balance (mm) & $11.2 \pm 10.3$ & $11.7 \pm 8.8$ & 0.891 \\
\hline Major Curve $<50^{\circ}$ & $36(92.3 \%)$ & $3(7.7 \%)$ & $0.137^{*}$ \\
\hline$\geq 50^{\circ}$ & $19(76.0 \%)$ & $6(24.0 \%)$ & \\
\hline Sex of patients Male & $3(60.0 \%)$ & $2(40.0 \%)$ & $0.141^{*}$ \\
\hline Female & $52(88.1 \%)$ & 7 (11.9\%) & \\
\hline Planed surgery Yes & 29 (82.9\%) & $6(17.1 \%)$ & $0.494^{*}$ \\
\hline No & $26(89.7 \%)$ & $3(10.3 \%)$ & \\
\hline MDD of patients No & $52(88.1 \%)$ & $7(11.9 \%)$ & $0.141^{*}$ \\
\hline Yes & $3(60.0 \%)$ & $2(40.0 \%)$ & \\
\hline GAD of patients No & $53(85.5 \%)$ & $9(14.5 \%)$ & $1.000^{*}$ \\
\hline Yes & $2(100.0 \%)$ & $0(0.0 \%)$ & \\
\hline Shoulder height Equal & 15 (93.8\%) & $1(6.2 \%)$ & $0.430^{*}$ \\
\hline Unequal & $40(83.3 \%)$ & $8(16.7 \%)$ & \\
\hline Brace treatment Yes & $16(84.2 \%)$ & $3(15.8 \%)$ & $1.000^{*}$ \\
\hline No & 39 (86.7\%) & $6(13.3 \%)$ & \\
\hline Age of parents & $42.3 \pm 3.9$ & $43.8 \pm 6.4$ & 0.326 \\
\hline Parenthood Father & $16(94.1 \%)$ & $1(5.9 \%)$ & $0.424^{*}$ \\
\hline Mother & $39(83.0 \%)$ & $8(17.0 \%)$ & \\
\hline $\begin{array}{l}\text { Education of parents Primary/ } \\
\text { Junior school }\end{array}$ & $15(75.0 \%)$ & $5(25.0 \%)$ & $0.124^{*}$ \\
\hline Senior school/University & 40 (90.9\%) & $4(9.1 \%)$ & \\
\hline Job of parents Yes & 38 (90.5\%) & $4(9.5 \%)$ & $0.254^{*}$ \\
\hline No & $17(77.3 \%)$ & $5(22.7 \%)$ & \\
\hline Health Insurance Yes & $44(86.3 \%)$ & $7(13.7 \%)$ & $1.000^{*}$ \\
\hline No & $11(84.6 \%)$ & $2(15.4 \%)$ & \\
\hline Residence City & $48(87.3 \%)$ & $7(12.7 \%)$ & $0.602^{*}$ \\
\hline Countryside & 7 (77.8\%) & $2(22.2 \%)$ & \\
\hline Parental Marriage Married & $50(86.2 \%)$ & $8(13.8 \%)$ & $1.000^{*}$ \\
\hline Divorced/widowed & $5(83.3 \%)$ & $1(16.7 \%)$ & \\
\hline Live with parents Yes & $53(86.9 \%)$ & $8(13.1 \%)$ & $0.370^{*}$ \\
\hline No & $2(100.0 \%)$ & $1(0.0 \%)$ & \\
\hline Income $<8000 \mathrm{rmb} /$ month & $32(78.0 \%)$ & $9(22.0 \%)$ & $0.021^{*}$ \\
\hline$\geq 8000 \mathrm{rmb} / \mathrm{month}$ & $23(100.0 \%)$ & $0(0.0 \%)$ & \\
\hline
\end{tabular}

* Fisher exact test

Low education level of the parents was an independent risk factor for parental pMDD. There is an inverse association between education attainment and depression, as reported previously [32]. In addition, the protective effect of education will increase somewhat with time throughout one's life [33].

Low household income ( $\leq 8000 \mathrm{rmb} /$ month) was the only risk factor for parental pGAD in this study. A similar relationship has been reported between low levels of household income and CMDs, including GAD [34]. This might be explained by social causation and social selection [35]. Social causation posits that adversity, stress, and reduced capacity to cope, as they relate to low income increase the risk of CMDs. The social selection hypothesis suggests that individuals with CMDs have a predisposition to declining socioeconomic status.

These findings support the recognition that the parents of children with AIS may suffer from CMDs and suggest the importance of conducting assessments of the parental psychosocial support needs. According to these risk factors, the screening need of the parents can be classified at two levels. It may help to first identify vulnerable parents, especially for those with risk factors, and then facilitate early referral for more focused assessment and interventions.

There were several limitations in this study. First, the sample size was limited, because it was a single center study. Second, we have not studied parents' coping strategies for meeting the stress of their children's illness. Future studies should be conducted with an objective study to research and discuss these coping factors.

\section{Conclusions}

The morbidities of pMDD and pGAD in parents of children with AIS were higher than those in parents with healthy children. Parental depression and anxiety were closely associated with their child's depression and anxiety. A Cobb angle of the major curve $\geq 50^{\circ}$, patients with pMDD, and low education level of the parents were the independent risk factors for parental pMDD. Low household income was the risk factor for parental pGAD. The parental mental health status of AIS patients should be paid attention to by deformity surgeons, especially for those parents with risk factors, it would help to facilitate early referral for more focused assessment and interventions. Insights into the parental coping strategies can help to guide treatment in the future research.

\section{Abbreviations}

95\%Cl: 95\% Confidence Interval; AIS: Adolescent Idiopathic Scoliosis; BSSQ: Bad Sobernheim Stress Questionnaire; CMDs: Common Mental Disorders; GAD-7: Seven-item Generalized Anxiety Disorder Scale; OR: Odds Ratio; pGAD: Probable Generalized Anxiety Disorder; PHQ-9: Nine-item Patient Health Questionnaire; pMDD: Probable Major Depressive Disorder; SF36: Short-Form-36; SRS-22: Scoliosis Research Society 22 Questionnaire

\section{Acknowledgements}

Not applicable.

Funding

No funds were received in support of this work.

Availability of data and materials

The datasets used and/or analyzed during the current study are available from the corresponding author on reasonable request. 


\section{Authors' contributions}

All authors made substantive intellectual contributions to this study to qualify as authors. HW and TL contributed to acquisition of data, analysis of data, statistical analysis, and interpretation of results. WY and ZZ contributed to acquisition of data. JW and GQ contributed to study design and study coordination. JS contributed to study design, study coordination, and manuscript preparation. All authors read and approved the final manuscript.

\section{Ethics approval and consent to participate}

This study was approved by the Ethics Committee of Peking Union Medical College Hospital. All the participants were orally informed, and the parents gave their written consent

\section{Consent for publication}

Not applicable.

\section{Competing interests}

The authors declare that they have no competing interests.

\section{Publisher's Note}

Springer Nature remains neutral with regard to jurisdictional claims in published maps and institutional affiliations.

\section{Author details}

'Department of Orthopaedic Surgery, Peking Union Medical College Hospital, Peking Union Medical College and Chinese Academy of Medical Sciences, Beijing, China. ${ }^{2}$ Department of Psychology, Peking Union Medical College Hospital, Peking Union Medical College and Chinese Academy of Medical Sciences, Beijing, China. ${ }^{3}$ Department of Rehabilitation, Peking Union Medical College Hospital, Peking Union Medical College and Chinese Academy of Medical Sciences, Beijing, China. ${ }^{4}$ Department of Orthopaedic Surgery, Beijing Puren Hospital, Beijing, China.

\section{Received: 17 October 2018 Accepted: 26 April 2019}

\section{Published online: 14 May 2019}

\section{References}

1. Trobisch P, Suess O, Schwab F. Idiopathic scoliosis. Dtsch Arztebl Int. 2010; 107(49):875-83 quiz 884

2. von Heideken J, Iversen MD, Gerdhem P. Rapidly increasing incidence in scoliosis surgery over 14 years in a nationwide sample. Eur Spine J. 2018; 27(2):286-92.

3. Ueno M, Takaso M, Nakazawa T, Imura T, Saito W, Shintani R, Uchida K, Fukuda M, Takahashi K, Ohtori S, et al. A 5-year epidemiological study on the prevalence rate of idiopathic scoliosis in Tokyo: school screening of more than 250,000 children. J Orthop Sci. 2011;16(1):1-6.

4. Plaszewski M, Nowobilski R, Kowalski P, Cieslinski M. Screening for scoliosis: different countries' perspectives and evidence-based health care. Int J Rehabil Res. 2012;35(1):13-9.

5. Rainoldi L, Zaina F, Villafane JH, Donzelli S, Negrini S. Quality of life in normal and idiopathic scoliosis adolescents before diagnosis: reference values and discriminative validity of the SRS-22. A cross-sectional study of 1,205 pupils. Spine J. 2015;15(4):662-7.

6. Asher MA, Min Lai S, Burton DC. Further development and validation of the Scoliosis Research Society (SRS) outcomes instrument. Spine (Phila Pa 1976). 2000;25(18):2381-6.

7. Botens-Helmus $C$, Klein $R$, Stephan C. The reliability of the Bad Sobernheim stress questionnaire (BSSQbrace) in adolescents with scoliosis during brace treatment. Scoliosis. 2006:1:22.

8. Bridwell KH, Shufflebarger HL, Lenke LG, Lowe TG, Betz RR, Bassett GS. Parents' and patients' preferences and concerns in idiopathic adolescent scoliosis: a cross-sectional preoperative analysis. Spine (Phila Pa 1976). 2000; 25(18):2392-9.

9. Sanders JO, Polly DW Jr, Cats-Baril W, Jones J, Lenke LG, O'Brien MF, Stephens Richards B, Sucato DJ. Group AISSotSDS: analysis of patient and parent assessment of deformity in idiopathic scoliosis using the Walter reed visual assessment scale. Spine (Phila Pa 1976). 2003;28(18):2158-63.

10. Rinella A, Lenke L, Peelle M, Edwards C, Bridwell KH, Sides B. Comparison of SRS questionnaire results submitted by both parents and patients in the operative treatment of idiopathic scoliosis. Spine (Phila Pa 1976). 2004;29(3):303-10.
11. Smith PL, Donaldson S, Hedden D, Alman B, Howard A, Stephens D, Wright JG. Parents' and patients' perceptions of postoperative appearance in adolescent idiopathic scoliosis. Spine (Phila Pa 1976). 2006;31(20):2367-74.

12. Misterska E, Glowacki M, Latuszewska J. Female patients' and parents' assessment of deformity- and brace-related stress in the conservative treatment of adolescent idiopathic scoliosis. Spine (Phila Pa 1976). 2012; 37(14):1218-23.

13. Lamontagne LL, Hepworth JT, Salisbury MH, Riley LP. Optimism, anxiety, and coping in parents of children hospitalized for spinal surgery. Appl Nurs Res. 2003;16(4):228-35.

14. Matcham F, Norton S, Steer S, Hotopf M. Usefulness of the SF-36 health survey in screening for depressive and anxiety disorders in rheumatoid arthritis. BMC Musculoskelet Disord. 2016;17:224

15. Kroenke K, Spitzer RL, Williams JB. The PHQ-9: validity of a brief depression severity measure. J Gen Intern Med. 2001;16(9):606-13.

16. Moriarty AS, Gilbody S, McMillan D, Manea L. Screening and case finding for major depressive disorder using the patient health questionnaire (PHQ-9): a meta-analysis. Gen Hosp Psychiatry. 2015;37(6):567-76.

17. He XY, Li CB, Qian J, Cui HS, Wu WY. Reliability and validity of a generalized anxiety disorder scale in general hospital outpatient. Shanghai Arch Psychiatry. 2010;22(4):200-3.

18. Lowe B, Decker O, Muller S, Brahler E, Schellberg D, Herzog W, Herzberg PY. Validation and standardization of the generalized anxiety disorder screener (GAD-7) in the general population. Med Care. 2008;46(3):266-74.

19. Spitzer RL, Kroenke K, Williams JB, Lowe B. A brief measure for assessing generalized anxiety disorder: the GAD-7. Arch Intern Med. 2006;166(10): 1092-7.

20. Swineford LB, Guthrie W, Thurm A. Convergent and divergent validity of the Mullen scales of early learning in young children with and without autism spectrum disorder. Psychol Assess. 2015;27(4):1364-78.

21. Raina P, O'Donnell M, Schwellnus H, Rosenbaum P, King G, Brehaut J, Russell D, Swinton M, King S, Wong M, et al. Caregiving process and caregiver burden: conceptual models to guide research and practice. BMC Pediatr. 2004:4(1).

22. Gowen JW, Johnson-Martin N, Goldman BD, Appelbaum M. Feelings of depression and parenting competence of mothers of handicapped and nonhandicapped infants: a longitudinal study. Am J Ment Retard. 1989; 94(3):259-71.

23. Stundner O, Kirksey M, Chiu YL, Mazumdar M, Poultsides L, Gerner P, Memtsoudis SG. Demographics and perioperative outcome in patients with depression and anxiety undergoing total joint arthroplasty: a populationbased study. Psychosomatics. 2013;54(2):149-57.

24. Strine TW, Mokdad AH, Balluz LS, Gonzalez O, Crider R, Berry JT, Kroenke K. Depression and anxiety in the United States: findings from the 2006 behavioral risk factor surveillance system. Psychiatr Serv. 2008:59(12):1383-90.

25. Uliaszek AA, Zinbarg RE, Mineka S, Craske MG, Sutton JM, Griffith JW, Rose R Waters A, Hammen C. The role of neuroticism and extraversion in the stress-anxiety and stress-depression relationships. Anxiety Stress Coping. 2010:23(4):363-81.

26. Eysenck MW, Fajkowska M. Anxiety and depression: toward overlapping and distinctive features. Cogn Emot. 2017:1-10.

27. Wesseldijk LW, Dieleman GC, van Steensel FJA, Bartels M, Hudziak JJ, Lindauer RJL, Bogels SM, Middeldorp CM. Risk factors for parental psychopathology: a study in families with children or adolescents with psychopathology. Eur Child Adolesc Psychiatry. 2018.

28. Connell AM, Goodman SH. The association between psychopathology in fathers versus mothers and children's internalizing and externalizing behavior problems: a meta-analysis. Psychol Bull. 2002;128(5):746-73.

29. Sisk RJ. Caregiver burden and health promotion. Int J Nurs Stud. 2000; 37(1):37-43.

30. Helbig $\mathrm{S}$, Lampert $\mathrm{T}$, Klose M, Jacobi F. Is parenthood associated with mental health? Findings from an epidemiological community survey. Soc Psychiatry Psychiatr Epidemiol. 2006;41(11):889-96

31. Silva MLA, Cardoso G. Social determinants of mental health: a review of the evidence. Eur J Psychiatry. 2016;30(4):259-92.

32. Lorant V, Deliege D, Eaton W, Robert A, Philippot P, Ansseau M Socioeconomic inequalities in depression: a meta-analysis. Am J Epidemiol. 2003:157(2):98-112

33. Bjelland I, Krokstad S, Mykletun A, Dahl AA, Tell GS, Tambs K. Does a higher educational level protect against anxiety and depression? The HUNT study. Soc Sci Med. 2008;66(6):1334-45. 
34. Sareen J, Afifi TO, McMillan KA, Asmundson GJ. Relationship between household income and mental disorders: findings from a population-based longitudinal study. Arch Gen Psychiatry. 2011;68(4):419-27.

35. Dohrenwend BP, Levav I, Shrout PE, Schwartz S, Naveh G, Link BG, Skodol AE, Stueve A. Socioeconomic status and psychiatric disorders: the causationselection issue. Science. 1992;255(5047):946-52.

Ready to submit your research? Choose BMC and benefit from:

- fast, convenient online submission

- thorough peer review by experienced researchers in your field

- rapid publication on acceptance

- support for research data, including large and complex data types

- gold Open Access which fosters wider collaboration and increased citations

- maximum visibility for your research: over $100 \mathrm{M}$ website views per year

At $\mathrm{BMC}$, research is always in progress.

Learn more biomedcentral.com/submissions 